\title{
Stem cell therapy to protect and repair the developing brain: a review of mechanisms of action of cord blood and amnion epithelial derived cells
}

\author{
Margie Castillo-Melendez ${ }^{1+}$, Tamara Yawno ${ }^{1+}$, Graham Jenkin ${ }^{1,2}$ and Suzanne L. Miller ${ }^{1,2 *}$ \\ 1 The Ritchie Centre, Monash Institute of Medical Research, Monash University, Clayton, VIC, Australia \\ ${ }^{2}$ Department of Obstetrics and Gynaecology, Monash University, Clayton, VIC, Australia
}

Edited by:

Sarah J. Spencer, Monash

University, Australia

Reviewed by:

Rafael Vazquez-Martinez, University

of Cordoba, Spain

Trisha A. Jenkins, RMIT University,

Australia

Nicolette Hodyl, University of

Adelaide, Australia

\section{*Correspondence:}

Suzanne L. Miller, Department of

Obstetrics and Gynaecology, The

Ritchie Centre, Monash Institute of

Medical Research, Monash

University, Level 3, 27-31 Wright St.,

Clayton, VIC 3168, Australia

e-mail: suzie.miller@monash.edu

these authors have contributed equally to this work.
In the research, clinical, and wider community there is great interest in the use of stem cells to reduce the progression, or indeed repair brain injury. Perinatal brain injury may result from acute or chronic insults sustained during fetal development, during the process of birth, or in the newborn period. The most readily identifiable outcome of perinatal brain injury is cerebral palsy, however, this is just one consequence in a spectrum of mild to severe neurological deficits. As we review, there are now clinical trials taking place worldwide targeting cerebral palsy with stem cell therapies. It will likely be many years before strong evidence-based results emerge from these trials. With such trials underway, it is both appropriate and timely to address the physiological basis for the efficacy of stem-like cells in preventing damage to, or regenerating, the newborn brain. Appropriate experimental animal models are best placed to deliver this information. Cell availability, the potential for immunological rejection, ethical, and logistical considerations, together with the propensity for native cells to form teratomas, make it unlikely that embryonic or fetal stem cells will be practical. Fortunately, these issues do not pertain to the use of human amnion epithelial cells (hAECs), or umbilical cord blood (UCB) stem cells that are readily and economically obtained from the placenta and umbilical cord discarded at birth. These cells have the potential for transplantation to the newborn where brain injury is diagnosed or even suspected. We will explore the novel characteristics of hAECs and undifferentiated UCB cells, as well as UCB-derived endothelial progenitor cells (EPCs) and mesenchymal stem cells (MSCs), and how immunomodulation and anti-inflammatory properties are principal mechanisms of action that are common to these cells, and which in turn may ameliorate the cerebral hypoxia and inflammation that are final pathways in the pathogenesis of perinatal brain injury.

Keywords: Perinatal brain injury, stem cells, umbilical cord blood, amnion epithelial cells, cerebral palsy, clinical trials, hypoxia/ischemia, inflammation

\section{PERINATAL HYPOXIC-ISCHEMIC BRAIN INJURY}

The neurological consequences of a severe hypoxic-ischemic insult in the human brain at term birth are often dire, with resultant hypoxic ischemic encephalopathy (HIE) a principal cause of newborn death or permanent neurological disability, such as cerebral palsy (Johnston et al., 2011; Volpe, 2012). At risk neonates include those who show signs of fetal distress prior to delivery, have abnormal Apgar scores and require resuscitation at birth, and show specific neurological abnormalities during the first $24 \mathrm{~h}$ after delivery (Perlman, 2004). Although the underlying causes and exact timing of brain injury in HIE infants are not always known, there may be a principal severe intrapartum hypoxicischemic insult at birth caused by placental abruption, umbilical cord prolapse, or prolonged labor, but there may also be precipitating antenatal risk factors (such as preeclampsia, antenatal bleeding, or intrauterine growth restriction) (Itoo et al., 2003; Paolo, 2012).

The progression from hypoxic-ischemic insult through to mass cell death within the perinatal brain has been extensively examined and reviewed (Volpe, 2001a, 2012; Ferriero, 2004; Gunn and Bennet, 2009). It may be described as a series of phases beginning with the primary insult and energy depletion through to subsequent reperfusion-induced cell death cascades. Both human neuroimaging and experimental animal studies demonstrate that damage to the developing brain evolves over days and possibly weeks (Ferriero, 2004). In human infants, neuronal cell death occurs in a series of chronological phases after the original hypoxic-ischemic insult (Penrice and Nussey, 1992; Azzopardi and Edwards, 2010), a finding that has been explored in greater detail in animal models of perinatal brain injury (Berger and Garnier, 2000; Gunn and Bennet, 2009). Primary neuronal death, in response to the insult, occurs due to cellular hypoxia and exhaustion of high-energy stores (primary energy failure). After return of cerebral perfusion and oxygenation, the hypoxia-induced cytotoxic oedema and accumulation of excitatory amino acids often resolves, together with recovery of the depressed metabolic state of the brain. However, cerebral oxidative metabolism may deteriorate in the hours following 
an asphyxic period, and this phase may last for many days. This secondary energy failure can be marked by the onset of seizures, further oedema, accumulation of excitotoxins and cytotoxic inflammatory substances, failure of cerebral mitochondrial activity and ultimately cell death (Gunn and Thoresen, 2006). The duration and severity of this second, delayed wave of cerebral compromise is closely associated with the degree of neurodevelopmental compromise at 1 year of age (Roth et al., 1992). By analogy with events that occur in the adult brain after stroke or traumatic brain injury, the damage arising during the "recovery" phase is thought to be due to vascular paralysis, enhancement of inflammatory processes, free radical formation, and breakdown of the blood-brain barrier. Similarly in the developing brain, we and others have shown that increased free radical formation (Miller et al., 2005) and oedema (Bennet et al., 2007) occur in the fetal sheep brain model of brief acute in utero asphyxia, suggesting that the coupling of oxidative metabolism, oxygen supply, and cerebral blood flow remain disturbed for some hours after such events.

Presently, the only treatment available for babies diagnosed with HIE soon after birth is to initiate hypothermia therapy. Hypothermia as a therapeutic intervention has been extensively investigated in human newborns (Gunn et al., 1998; Shankaran et al., 2005; Simbruner et al., 2010; Higgins et al., 2011), where hypothermia, after severe hypoxia-ischemia at birth, lowers the incidence of death or major disability, resulting in significant improvements in babies with moderate, but not severe, HIE (Shankaran et al., 2005; Higgins et al., 2011). The principal mechanisms of hypothermia-induced neuroprotection are likely to be multi-modal, with hypothermia functioning to reduce brain perfusion and metabolism, decrease secondary energy failure and oxidative stress leading to recovery of cerebral oxidative metabolism, and a subsequent reduction in programmed cell death (Katz et al., 2004). However, despite demonstrated efficacy, when hypothermia is effectively applied $40-50 \%$ of infants will still die or suffer significant neurologic disability following treatment (Edwards et al., 2010; Massaro et al., 2013). Furthermore, variations currently exist in the mode of administration of therapeutic hypothermia (Harris et al., 2013) and to be effective, hypothermia to treat HIE must commence within $6 \mathrm{~h}$ after birth, indicative that the "window of opportunity" to reduce the progression of brain injury is limited to the immediate hours after the insult (Vannucci and Perlman, 1997; Gunn et al., 2005; Higgins et al., 2011). This is in contrast to the adult brain, where it has been shown that treatment options extend over several hours post insult and possibly days following a severe hypoxic-ischemic event (Horn and Schlote, 1992). However, any therapeutic intervention that exists to limit the degree of newborn brain injury is extremely encouraging and provides a basis and the impetus to further refine and develop new or adjunct neuroprotective treatments. Therapies that can complement and provide additive benefit to hypothermia must be considered where the principal aim is to prevent or reduce the progression of mass programmed cell death. Alternatively, where a lack of perinatal brain injury diagnosis or other logistical factors, such as availability of tertiary care, preclude therapies within the hours that comprise the window of opportunity, we must look toward alternative strategies such as cell based therapies that could provide regenerative and repair capacity within the young brain.

It should also be considered that while term hypoxic-ischemic brain injury, and subsequent HIE, is a condition that is readily identifiable and therefore amenable to treatment, there are other significant chronic or acute causal factors that contribute to perinatal brain injury and neurodevelopmental deficits. Most notably, in infants born preterm and in infants exposed to intrauterine inflammation (chorioamnionitis), white matter brain injury, which often manifests as periventricular leukomalacia, is the most common form of brain injury (Volpe, 2001b; Yoon et al., 2003). In turn, periventricular white matter injury is the predominant neuropathology observed in children with cerebral palsy (Leviton and Paneth, 1990). Defining the time of onset and evolution of white matter damage to the preterm brain is considerably more challenging than delineating injury progression in response to term hypoxia-ischemia. However, it is known that hypoxiaischemia and upregulation of inflammatory processes are final common pathways contributing to periventricular white matter brain injury in the newborn (Volpe, 2001b; Yoon et al., 2003; Titomanlio et al., 2011).

\section{STEM CELL THERAPY FOR PERINATAL BRAIN INJURY}

Experimental clinical and animal studies have begun to elucidate the utility of stem cell-based therapies to prevent or repair perinatal brain injury. Predominantly, these cells have been derived either from neuronal embryonic or adult tissue (neural stem cells), or from non-neural origin such as those isolated from bone marrow and umbilical cord. Neural stem cells are self-renewing and give rise to neurons, astrocytes, and oligodendrocytes. Experimentally, these cells appeared to hold great promise for neural repair after injury, including in perinatal hypoxic ischemic brain injury (Felling et al., 2006; Daadi et al., 2013), however, the therapeutic benefits of transplantation of neural stem cells have not previously been convincingly shown (Andressen, 2013). Neural stem cells are difficult to harvest, lack homogeneity, and are found in very low numbers in the central nervous system (Sommer and Rao, 2002). Stem cell therapies offer promising treatment potential, with the exciting prospect that stem cells may be able to act via a variety of diverse actions at different phases of brain injury progression. However, in addition to consideration of their efficacy, it is important to reflect on ethical concerns, accessibility, and abundance of stem cells for clinical applications. Accordingly, in this paper we will review stem cell-based therapies using human amnion epithelial cells (hAECs) and umbilical cord blood (UCB) derived cells; each with the potential to interrupt both the evolutionary progression of perinatal brain injury when the timing of the adverse insult is known, or to provide regenerative capacity when the insult may have occurred in utero and may, therefore, present as more advanced neuropathology. Both hAECs and UCB can be easily and economically obtained at human birth, from tissues that are otherwise discarded. Accordingly, with the prospect that each of these cell lineages display independent protective and reparative properties, we raise the intriguing possibility for autologous neuroprotective therapies for the newborn brain in babies identified at-risk of brain injury. 


\section{HUMAN AMNION EPITHELIAL CELLS (hAECs)}

Over the past decade there has been growing interest in the reparative properties and potential uses of hAECs in treating organ injury, including the rescue of adult neurodegenerative or acute-onset brain disorders (Yang et al., 2010; Broughton et al., 2013). The human amniotic membrane is formed from the epiblast on or around the eighth day after fertilization and before gastrulation, and constitutes the inner layer of the amnion surrounding the fetus (Akle et al., 1981). The human amniotic membrane has key functions in pregnancy and embryonic development; it has anti-inflammatory and immunological properties that act to suppress the immune response against the fetus, has multiple metabolic and transport functions and may contribute to the onset and progression of uterine contractility (Mamede et al., 2012). The cell populations within amniotic membrane demonstrate pluripotent properties, reflecting the origin of this membrane in utero, but also providing a rationale for clinical applications of these cells (Parolini et al., 2008).

The innermost layer of the human amnion is $8-12 \mu \mathrm{m}$ thick and consists of a single layer of homogeneous cuboidal epithelial cells, so-called hAECs (Hebertson et al., 1986; Iwasaki et al., 2003). hAECs display many characteristics of both embryonic and pluripotent stem cells, with the potential to differentiate into a range of cell types (Ilancheran et al., 2007; Parolini et al., 2008). The amniotic fluid is also a source of cells with similar characteristics to hAECs. The heterogenous population of cells obtained from amniotic fluid at amniocentesis, have a diverse capacity to differentiate and, as for hAECs, may thus offer novel therapeutic potential (De Coppi et al., 2007). Both amniotic fluid-derived stem cells and hAECs are positive for CD117 (c-Kit) which is a transmembrane protein that functions as a tyrosine kinase receptor-a receptor that is also present on embryonic stem cells, primordial germ cells and somatic stem cells including neural crest cells-however, amniotic fluidderived stem cells also appear distinct from hAECs on the basis of differences in many cell surface markers and in gene expression patterns assessed by transcriptional profiling (Hipp and Atala, 2006; Murphy et al., 2010). hAECs themselves have low immunogenicity (Bailo et al., 2004) and indeed, rather than eliciting an immune response, they can reduce such a response by inhibiting both innate and adaptive immune system cells (Li et al., 2005). The role of hAECs in immunomodulation appears multi-factorial, characterized by suppression of proinflammatory cytokines (Solomon et al., 2001), regulation of macrophage recruitment (Tan et al., 2013) and secretion of factors that inhibit the chemotactic activity of neutrophils and macrophages (Li et al., 2005). These properties of hAECs, as summarized in Figure 1, are very attractive when considering the potential for cell-based therapies for treatment of brain injury. Additionally amnion can be easily collected in a non-invasive manner from the placenta which is discarded in $\sim 300,000$ Australian births each year and hAECs can be isolated and stored for later clinical use, without the need for expansion (Murphy et al., 2010). In this respect, hAECs are readily available and their use avoids the ethical issues that remain one of the major limitations for the therapeutic use of embryonic stem cells (Yu et al., 2009).

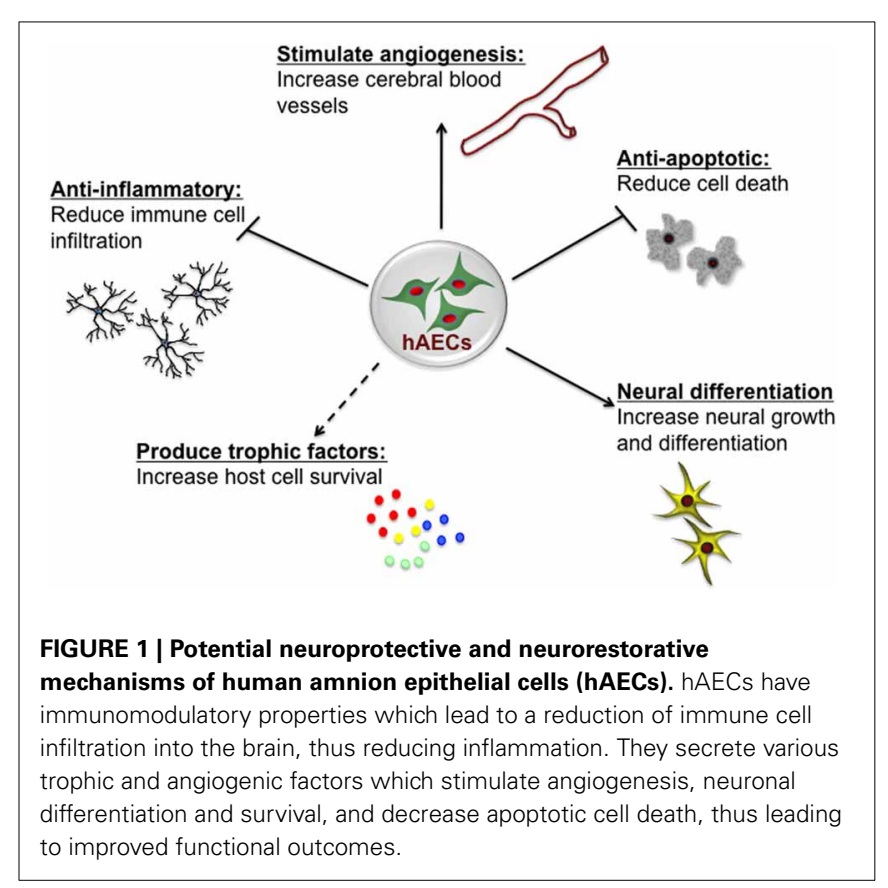

\section{PERINATAL HYPOXIC-ISCHEMIC BRAIN INJURY AND hAECs}

Emerging evidence demonstrates the broad potential of hAECs in the treatment of brain injury. Naïve hAECs express specific neural marker genes, including neuro filament-M, myelin basic protein, microtubule-associated protein 2, and glial fibrillary acid protein (Mahmood et al., 2005), and cultured hAECs can be directed toward a neural lineage, differentiating into neurons and astrocytic cells (Sakuragawa et al., 1996; Ilancheran et al., 2007; Toda et al., 2007). In culture, naïve, undifferentiated hAECs are also reported to synthesize and secrete neurotransmitters including catecholamines, acetylcholine, and neurotrophic factors (Sakuragawa et al., 1997; Elwan et al., 1998; Kakishita et al., 2000).

The neural differentiation capacity and neurotrophic potential of hAECs has been examined in animal models of adult brain pathology. In a rat experimental model of Parkinson's disease [induced by 6-hydroxydopamine (6-OHDA) administration, and causing multiple lesions], transplanted hAECs prevented the death of dopaminergic neurons, mediated by the active secretion of neurotrophic factors (Kakishita et al., 2000). In ischemic stroke induced by middle cerebral artery occlusion in adults rats, intra-cerebral injection of hAECs improved functional recovery and decreased ischemic infarct volume, when compared with non-hAEC treated rats (Liu et al., 2008). Although intra-cerebral injections of such cells are unlikely to be promoted for treatment of either adult or neonatal brain injury, it has recently been shown that intravenous administration of amniotic fluid-derived stem cells promotes significant motor and cognitive recovery in rats subjected to ischemic stroke. Rats treated with amniotic fluid stem cells demonstrated a significant decrease in brain infarct volume and significantly increased endogenous cell proliferation within proliferative zones, compared to post-stroke rats that did not receive cell therapy (Tajiri et al., 2012). A recent literature review by Broughton and colleagues provide an overview of 
the mechanisms that contribute to ischemic stroke injury and explores the novel properties of hAECs and, to a lesser extent, amniotic fluid- derived stem cells, and the properties that make them appealing for stroke research (Broughton et al., 2013). Research in this field is still in its relative infancy, but certainly hAECs are considered a novel and promising cell-based therapy for ischemic and inflammatory adult brain injury.

In developing preterm fetal sheep, we have recently published data on the utility of hAECs to reduce organ injury and to elucidate the mechanisms by which hAECs have their effect (Vosdoganes et al., 2011; Hodges et al., 2012; Yawno et al., 2013). In particular, we have been interested in novel therapies to reduce or ameliorate inflammation-induced preterm lung and brain injury. hAECs (180 million cells) delivered at 0, 6, and $12 \mathrm{~h}$ relative to the time of inflammatory insult, mitigated structural lung injury in preterm fetal sheep in utero and were incorporated into lung tissue, albeit in relatively small numbers, where they differentiated into alveolar cells (Hodges et al., 2012). In response to intrauterine inflammation induced by intra-amniotic lipopolysaccharide, hAECs attenuated the fetal inflammatory response by decreasing the localized increase in pro-inflammatory cytokines within fetal lungs (Vosdoganes et al., 2011). In turn, we have also reported that, by attenuating the fetal inflammatory response, hAECs reduced fetal brain inflammation and reduced gray and white matter preterm brain injury (Yawno et al., 2013). The neuroprotective actions of hAECs in the fetal brain were likely via anti-inflammatory effects, whereby hAECs suppressed activated microglial cell upregulation within the developing brain, which we showed to be correlated with decreased cell death. A notable observation was that hAECs were able to ameliorate lipopolysaccharide-induced periventricular white matter injury, by preferentially protecting endogenous oligodendrocytes (Yawno et al., 2013). Our understanding of the principal actions of hAECs in the developing lung and brain have been extended in mice models of adult lung disease, where hAECs were shown to decrease macrophage infiltration in the lungs and to promote the reparative M2 "alternatively activated" phenotype of macrophages, with fewer M1 phenotype "classically activated" pro-inflammatory macrophages (Tan et al., 2013). In related experiments, hAECs have been shown to repair established adult lung damage; however, these reparative benefits were found to be dependent on the timing of hAEC administration. hAECs were most beneficial at day 14 and not when administered earlier at day 7 , during a time of peak inflammation. This likely reflects the evolution of the immune and inflammatory environment postinsult and that hAECs are not only capable of preventing injury but are also capable of repair once the injury is already established (Vosdoganes et al., 2012). Further studies in models of adult lung disease have demonstrated that the actions of hAECs were independent of tissue engraftment and, most likely, were due to factors released by hAECs rather than through direct effects of the hAECs themselves (Tan et al., 2013). The fact that hAECs may be capable of repairing established injury make them exciting and intriguing candidates for repairing damage to the developing brain, which is known to be mediated by inflammatory events and is often only revealed once injury has occurred. Furthermore, the fact that they can act via anti-inflammatory actions that are independent of tissue engraftment provides a rationale for development of therapies using the reparative factors, per se.

\section{UMBILICAL CORD BLOOD STEM CELLS}

UCB contains a rich and diverse mixture of stem and progenitor cells that have the potential to generate a variety of cell types (Ali and Bahbahani, 2010). In 1989, Broxmeyer, Gluckman, and colleagues demonstrated that UCB can be used in clinical settings for stem cell transplantation (Broxmeyer et al., 1989; Gluckman et al., 1989). Since then, UCB has been used to treat nearly 80 diseases with over 25,000 transplants worldwide. UCB represents an abundant source of non-embryonic stem cells which are easily accessible with non-invasive collection of cells and no risk to the donor. Such cells are more immature than their bone marrow derived counterparts and hence display an impressive proliferative potential (Tiwari et al., 2012; Tursky et al., 2012) and have good viability after cells have been cryopreserved for later use (Pipes and Ablin, 2006; Slatter et al., 2006). UCB stem cells have high engraftment rates when used for replacement of haematopoietic stem cell populations, are relatively tolerant of HLA mismatches and thereby show low rates of graft-vs.-host disease, compared to bone marrow derived stem cells (Swijnenburg et al., 2005). They are rarely contaminated with latent viruses resulting in greater acceptance of UCB stem cells in comparison to those from bone marrow. UCB has been widely used for the treatment of various hematopoietic disorders (Kurtzberg, 1996; Locatelli et al., 1998) but, of relevance to this review, they have more recently been shown to induce regeneration in the central nervous system (Harris and Rogers, 2007; Herranz et al., 2010).

UCB is rich in hemapoietic stem/progenitor cells, regulatory T-lymphocytes (Tregs), monocytes, mesenchymal stem cells (MSCs), endothelial progenitor cells (EPCs), and stromal precursor cells (Pimentel-Coelho et al., 2012) and, consequently, holds promising potential for the treatment of neurological disorders. Indeed, a recent pre-clinical study has shown that UCB transplantation resulted in improved sensorimotor ability in a rat model of hypoxic ischemic brain injury (Geissler et al., 2011). To our knowledge, there are currently only a modest number of animal studies that have examined the effects UCB transplantation following hypoxic-ischemic injury, predominantly in newborn rats. These experiments using the Rice-Vannuci animal model (Rice et al., 1981) have reported positive brain results following UCB transplantation including decreased reactive gliosis (Wasielewski et al., 2012), increased tissue repair, cognitive improvements (de Paula et al., 2012), amelioration of injury-related effects in the primary somatosensory cortex (Geissler et al., 2011) and enhancement of endogenous neural stem cell proliferation via Hedgehog signaling (Wang et al., 2013b). These pre-clinical trials have not yet fully elucidated the mechanism underlying the beneficial effects of UCB transplantation, and there are several important questions that must be addressed before findings can be translated to the bedside. Nevertheless, autologous intravenous UCB transplantation has been shown to be safe and feasible in young children with acquired neurological disorders (Buzanska et al., 2006).

With respect to neonatal brain injury, UCB transplantation is emerging as a promising therapeutic approach for treatment of 
hypoxic-ischemic brain injury and ischemic stroke (Wang et al., 2012). There are now a number of human clinical trials taking place to examine the potential therapeutic benefits of undifferentiated cord blood cells for the treatment of established ischemic brain injury and established cerebral palsy. For Table 1 we identified these trials through the ClinicalTrials.gov database using the following search terms: UCB + newborn + ischemic brain injury OR + cerebral palsy. Although some trials have now been completed, there have been no peer-reviewed reports of them published as yet. It is imperative that the timing of the administration of the UCB with respect to the time of the injury (if known) is defined, as well as the optimal dose of UCB for transplantation. Furthermore, the contribution and beneficial effects of the different cell populations that are present in UCB need to be elucidated in order to determine adequate therapies that could lead to further improvement in neurological outcome, based on the clinical scenario. We will further discuss two different cell types found in cord blood, which independently show promise in pre-clinical trials.

\section{ENDOTHELIAL PROGENITOR CELLS (EPCs)}

EPCs were originally identified as a population of stem cells in human peripheral blood and characterized by their expression of CD34, vascular endothelial receptor 2 (VEGFR-2), and CD133 markers (Asahara et al., 1997; Peichev et al., 2000). Subsequently, EPCs have been isolated from other sources, such as bone marrow, fetal liver, and UCB. Although no specific markers are currently available for EPCs, the early functional angioblast, located predominantly in the bone marrow are generally identified by three surface markers (CD133, CD34, and VEGF-2), while circulating EPCs (which have begun to mature into endothelial cells) are usually characterized by expression of endothelial markers such as VE-cadherin, endothelial nitric oxide synthase and von Willebrand factor (Hristov and Weber, 2004). EPCs are stem cells that are mobilized in response to acute hypoxia from bone marrow and released into the circulation. Endogenous EPCs act to maintain vascular integrity and homeostasis, and then, when required, they are able to mediate the response to, and the repair of, vascular injury. This reparative role is achieved by inducing endothelial cell repair and regeneration, and by promoting tissue neovascularization (Zhang et al., 2002). Experimental and human studies show that EPCs participate in neovascularization processes in ischemic organs, and hence their regulation could have therapeutic applications in vascular diseases (Zampetaki et al., 2008). In adult ischemic brain injury, such as occurs in stroke, transplanted EPCs home to the ischemic injury core, and promote cerebral neovascularization and neuron progenitor cell migration and survival (Zhang et al., 2002; Fan et al., 2010).

\section{EPCs, VASCULAR INTEGRITY AND REPAIR}

Maintaining the integrity of the vascular endothelial monolayer is extremely important, since it represents a barrier between the blood and subendothelial matrix proteins, but also restricts the infiltration of inflammatory cells, modulates vascular tone, and controls vascular smooth muscle proliferation (Zampetaki et al., 2008). The cerebrovascular system requires constant remodeling and dynamic adaptation of the vascular network in response to functional needs. In response to molecular cues that are initiated under conditions of hypoxia-ischemia, new blood vessel formation in adults has traditionally been understood to result primarily from angiogenesis, the process of local proliferation, migration, and remodeling of endothelial cells from a mature pre-existing endothelium (Red-Horse et al., 2007). This process is dependent upon an array growth factors, matrix metalloproteinases, cytokines, and integrins. To date, over 20 endogenous pro-angiogenic factors have been identified, including vascular endothelial growth factor (VEGF), platelet derived growth factor (PDGF), erythropoietin (EPO), and angiopoietin 1 and 2 (Ang1\&2; Figure 2). Angiogeneis begins with an increase in vascular permeability, followed by basement membrane and extracellular matrix degradation via matrix metalloproteinases (MMPs). Endothelial cells then initiate migration along newly deposited extracellular matrix tracts to form vessel sprouts. Finally, lumencontaining vessels are formed and integrated into the circulation (Red-Horse and Ferrara, 2006). From a therapeutic standpoint, the vasculature of the central nervous system has attracted attention since a number of human ailments such as stroke, retinopathy, cancer, and autoimmune disease are intimately associated with vasculopathy. Stem cells, most notably EPCs, show great potential as neurorestorative therapies as they target the basic components of the neurovascular unit (endothelial cells, astrocytes, pericytes and smooth muscle cells, neural stem cells, oligodendrocytes, and neurons) and the basic cellular elements that form the basement membrane.

With the discovery of EPCs, it was demonstrated that neovascularization after focal cerebral ischemia can also occur via vasculogenesis - the de novo process of blood vessel formation by differentiation and migration of EPCs in response to local cues (Figure 2). EPCs migrate locally to injured tissue and participate in neovacularization, regeneration of the injured endothelium, or wound healing by providing a proliferative pool of cells with the capacity to differentiate into mature vascular endothelial cells, and by secreting pro-angiogenic growth factors (Zampetaki et al., 2008). In this regard, EPCs are a potential tool for therapeutic angiogenesis. VEGF, MMP-9, and EPO are involved in the mobilization of EPCs into the circulation from the bone marrow (Zampetaki et al., 2008) and EPCs are recruited to new sites of vascularization, using cues that resemble an inflammatory response. The process of EPC homing to the site of injury includes detachment from the bone marrow niche, rolling into blood vessels, and traveling within the circulation. Once in the vicinity of an injured vessel, EPCs interact with the damaged endothelial monolayer in a similar way that leukocytes interact with activated endothelial cells. Thus, adhesion molecules previously identified as being involved in the inflammatory response, particularly leukocyte adhesion molecules (P-selectin, E-selectin, $\beta 2$-integrins) have now been identified as key regulators of EPC homing (Zampetaki et al., 2008). Systemic administration of umbilical cord blood-derived EPCs in adult mice results in significant protection against hypoxic-ischemic brain injury, with reduced infarct volume, decreased neutrophil infiltration, and increased focal blood flow at $48 \mathrm{~h}$ after ischemia (Ohta et al., 2006). Interestingly, this study also reported that circulating EPC levels were inversely correlated with cerebral infarction, but 


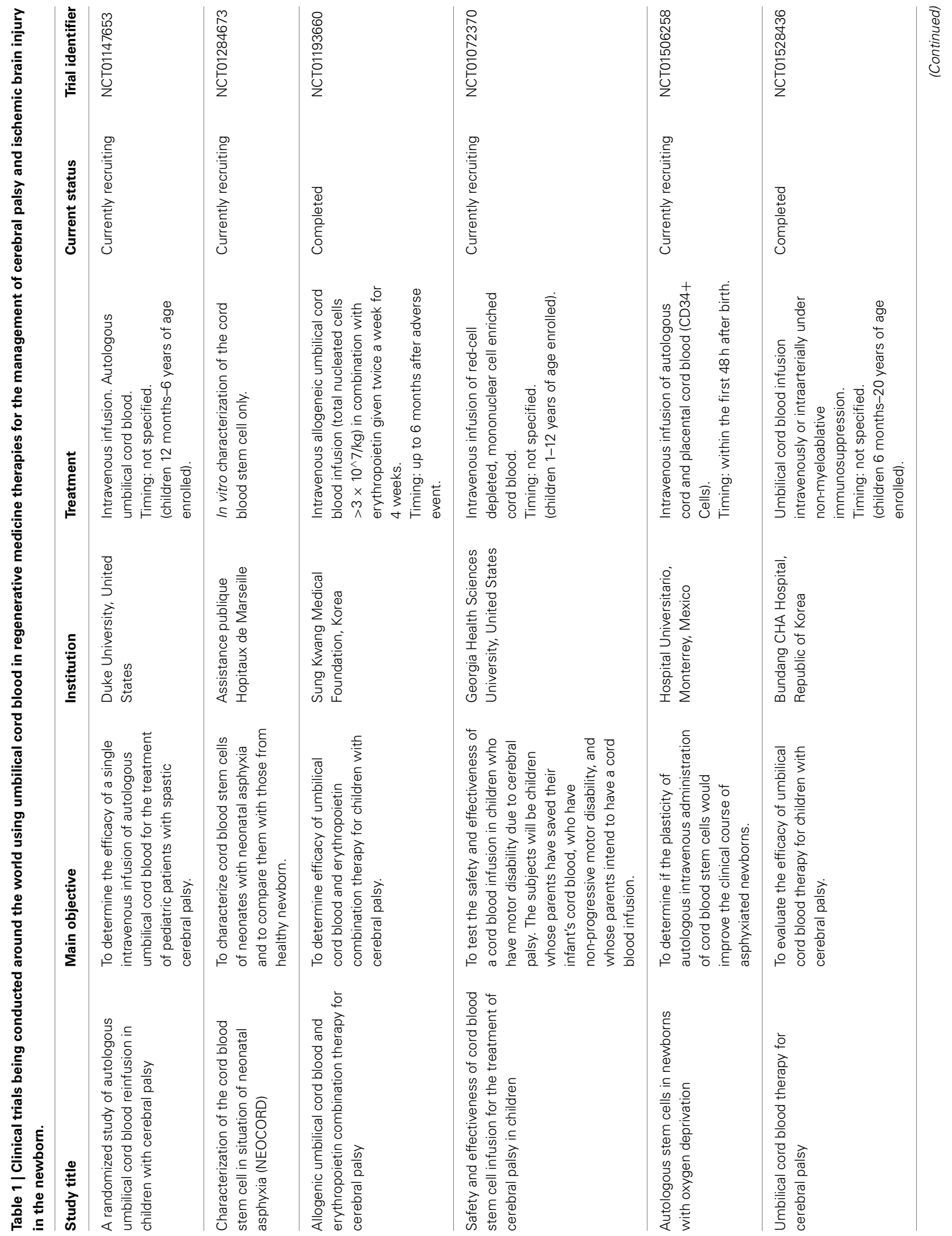




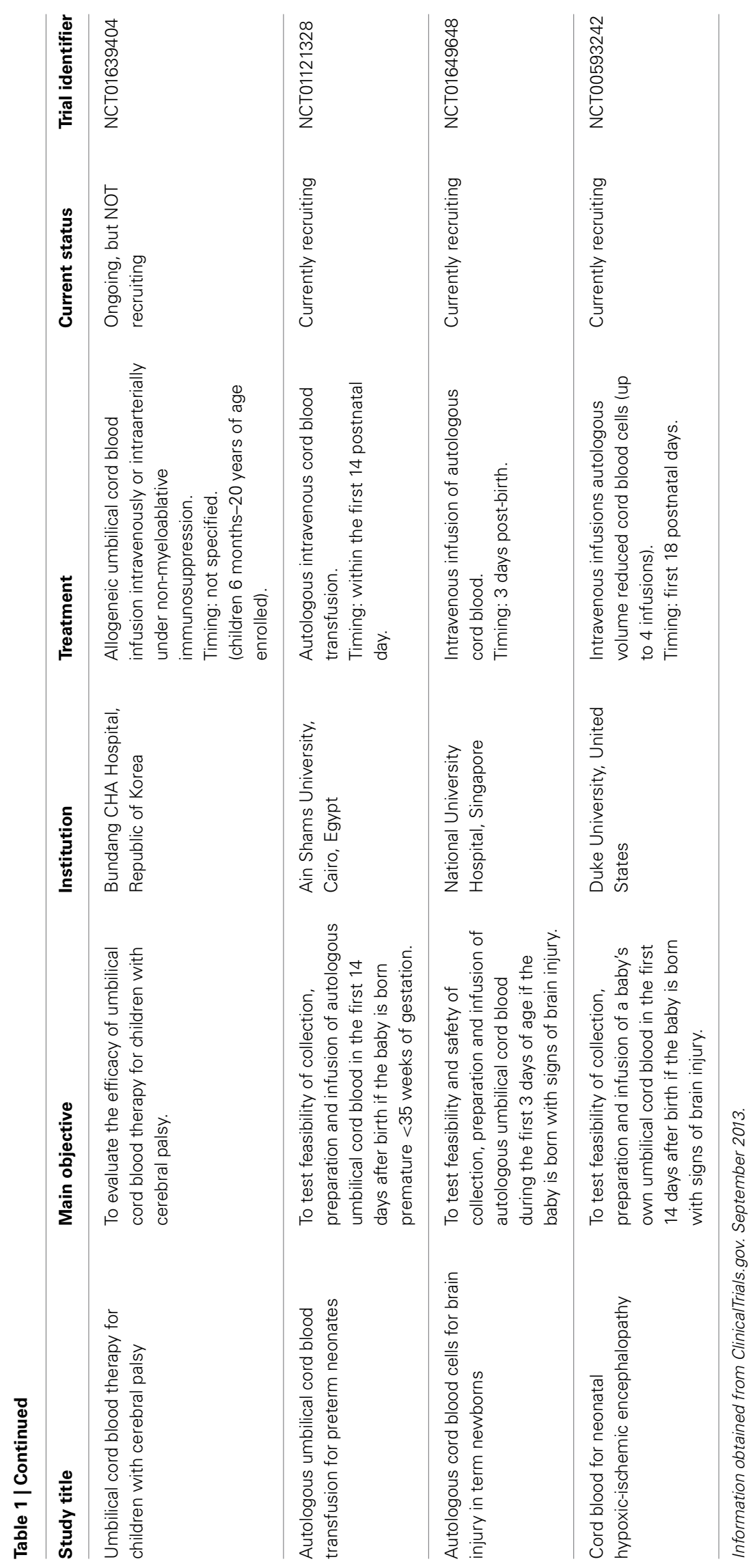




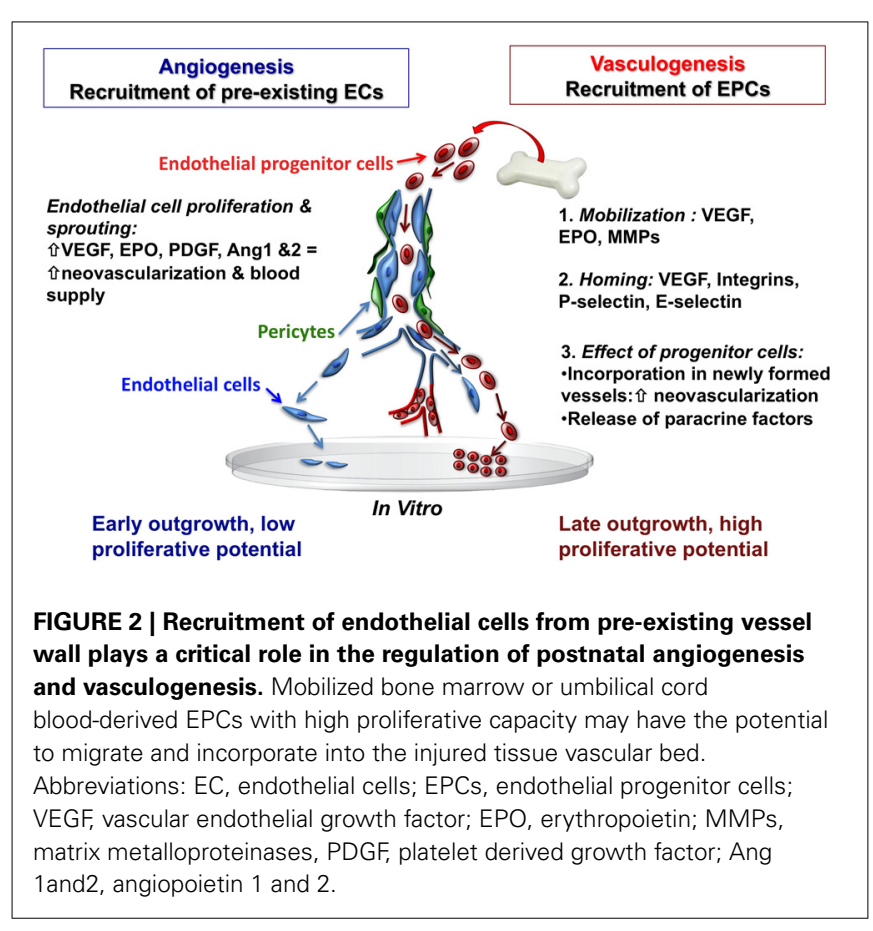

positively correlated with regional blood flow in hypoperfused areas of the brain after ischemia (Ohta et al., 2006), suggesting that EPCs may be a functional predictor of the wellbeing of cerebral vasculature. Additionally, the level of circulating EPCs and their migratory activity may serve as a marker for the risk of cardiovascular diseases, and even as a predictor of vascular function in many diseases (Vasa et al., 2001; Tepper et al., 2002; Baumhakel et al., 2006; Werner and Nickenig, 2006a,b).

\section{EPCs IN PREGNANCY AND THE FETUS}

EPCs circulate at very low levels in adult human blood, and their frequency and function may be secondarily impaired in response to various complications (Vasa et al., 2001; Tepper et al., 2002; Baumhakel et al., 2006; Werner and Nickenig, 2006a,b). In contrast, EPCs are enriched in term UCB, and cord blood EPCs have been shown to proliferate faster and show enhanced vessel forming ability in comparison to adult-derived EPCs (Yoder et al., 2007; Au et al., 2008). Furthermore, the average number of cell progeny that can be derived from a single plate of cord blood EPCs is reportedly 100 -fold greater when compared to those obtained from an adult, and can be serially replated and expanded exponentially in long-term culture (Ingram et al., 2004), suggesting that cord blood represents a rich source of EPCs, with the potential for storage in large quantities for clinical use.

In pregnancy, EPCs in the maternal circulation are present in the second trimester (Gussin et al., 2002), and the number of circulating EPCs increases gradually with gestational age (Sugawara et al., 2005). A more recent study measured circulating EPCs in cord blood at various stages of human gestation and found that in infants born at 24-28 weeks of gestational age, the cord blood yielded low levels of EPCs and high levels of MSCs, whereas at 33-36 weeks gestation the cord blood yielded higher levels of EPCs, equivalent to that found in term infants (Javed et al., 2008). This was confirmed in another study investigating circulating EPCs in preterm infants with bronchopulmonary dysplasia, finding that EPC levels were relatively low below 32 weeks gestation, and increased as pregnancy progressed. Additionally, they noted that extremely preterm infants with low levels of EPCs had an increased risk of developing bronchopulmonary dysplasia (Borghesi et al., 2009).

\section{MESENCHYMAL STEM CELLS (MSCs)}

MSCs are multi-potent cells with a strong capacity for selfrenewal, which can be isolated from a variety of tissues, such as bone marrow, adipose tissue, umbilical cord, and UCB. MSCs have the ability to differentiate into a variety of cell types, depending on cues from their microenvironment. MSCs have been studied for use in neurologically related cell-based therapy in adult experimental animal models and in clinical trials of human brain disorders, such as Parkinson's and Huntington's disease, traumatic brain injury, and stroke (Berry et al., 2006; Hermann et al., 2010; Zilka et al., 2011; Kitada and Dezawa, 2012). MSCs home to areas of insult, where they promote tissue repair via secretion of soluble factors that enhance tissue regeneration, stimulate proliferation, migration, and differentiation and survival of endogenous local progenitor cells found in the microenviroment, as well as by decreasing inflammatory and immune reactions and apoptosis (Caplan and Dennis, 2006; Yi et al., 2012).

Transplanted MSCs augment host repair and tissue recovery, primarily through trophic support that appears to be mediated by direct and indirect actions. MSCs secrete both soluble (cytokines, growth factors) and insoluble (extracellular matrix proteins) factors that promote neural cell survival and regeneration (neurogenesis, angiogenesis, and synaptogenesis) through paracrine signaling (Seo and Cho, 2012). Other protective actions that are particular to the brain include remyelination (Akiyama et al., 2012), and inhibition of apoptosis and inflammation (Caplan and Dennis, 2006). The proposed neuroprotective effects of MSCs are summarized in Figure 3.

\section{PROTECTIVE MECHANISMS OF MSCs IN BRAIN INJURY}

There is now solid preclinical data to demonstrate that MSC transplantation promotes functional recovery following experimental adult hypoxic ischemic brain injury or traumatic brain injury (Parr et al., 2007). The mechanisms by which MSCs regulate neural recovery and repair in brain tissue is now being extensively investigated, with a number of likely potential actions. In culture, MSCs can be directed toward, and may spontaneously generate, precursor and mature neuronal cells and cells of glial (astrocytic) lineage (Woodbury et al., 2000; Deng et al., 2006). When grafted into the lateral ventricle of the developing mouse brain, MSCs migrate over significant distances and preferentially differentiate into mature neurons and periventricular astrocytes (Deng et al., 2006), suggesting that MSCs are primed toward a neural fate. In addition to direct actions, MSCs secrete soluble factors capable of stimulating proliferation of neural stem cells in vitro, as well as increasing the expression of GFAP (a marker of mature astrocytes) (Galindo et al., 2011). Further studies confirm that MSCs activate neural stem cells or progenitor 


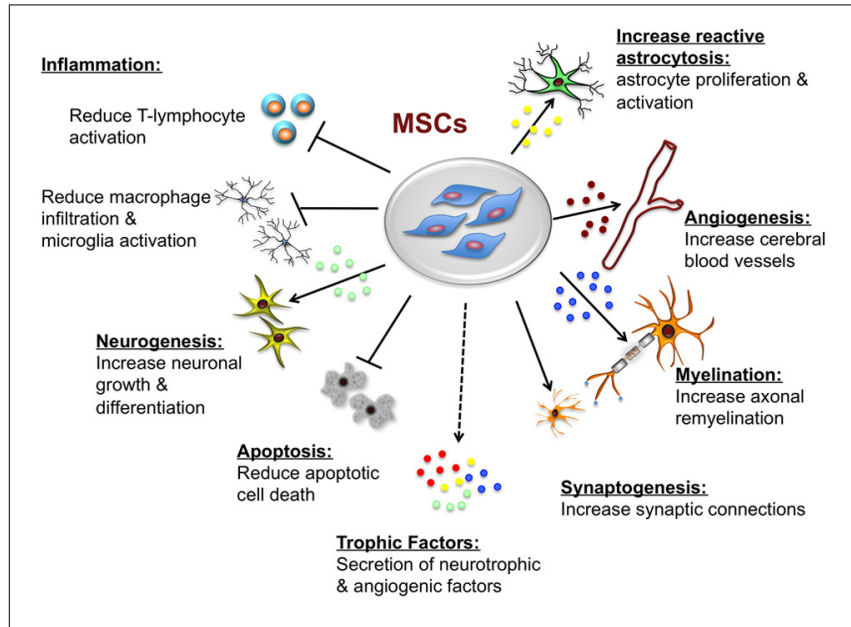

FIGURE 3 | Potential neuroprotective and neurorestorative effects of mesenchymal stem cells (MSCs). The beneficial actions of MSCs are mediated primarily by paracrine actions. MSCs secrete a number of neurotrophic and angiogenic factors that promote neuronal growth and differentiation, induce angiogenesis, neurogenesis and astroglial growth and activation, they promote synaptogenesis thus enhancing synaptic connections and axonal remyelination, decrease apoptosis, and decrease macrophage infiltration, and microglia and T-lymphocyte activation.

cells (Munoz et al., 2005, 2012), and are capable of undergoing expansion and differentiation into neurons, astrocytes, and oligodendrocytes both in vitro (Reynolds et al., 1992) and after transplantation in vivo (Alexanian et al., 2008; Kennea et al., 2013). In response to MSC transplantation after brain ischemia, there is an increase in new oligodendrocyte progenitor cells, mature oligodendrocytes, and myelin formation in the ischemic hemisphere (van Velthoven et al., 2011a). Transplantation of human MSCs into the injury penumbra of monkeys, one week following experimental cerebral ischemia, decreased apoptotic cell death, and the lesion volume (Li et al., 2010; Xin et al., 2010). In addition, Kim et al. (2010) showed that intravenous administration of human MSCs one day following traumatic brain injury in rats improved functional recovery and enhanced host cell survival by increasing pAkt and decreasing caspase-3 cleavage. Intravenous delivery of MSCs one day following experimental stroke in mice has also been shown to increase axon fiber density, synaptogenesis, and myelination (Xin et al., 2010). An important aspect of MSCs reparative role is the induction of trophic factors in response to injury cues; these include brain derived growth factor (BDNF), glial cell line-derived neurotrophic factor (GDNF), VEGF, fibroblast growth factor-2, and 7 (FGF-2, FGF-7), fibronectin, heparin binding-epidermal growth factorlike growth factor (HB-EGF), hepatocyte growth factor (HGF), interleukin-6 (IL-6), leukemia inhibitory factor (LIF), monocyte chemoattractant protein-1 (MCP-1), and PDGF (Li et al., 2002).

In addition to interacting directly with cells of the central nervous system, MSCs communicate with immune cells and have important immnosuppressive properties. MSCs suppress T- and B-cell proliferation, inhibit natural killer cell function, and modulate the secretory profile of microglia and macrophages (Le Blanc, 2003). Accordingly, treatment with MSCs is shown to decrease T-lymphocyte activity thereby exerting an immunoregulatory capacity (Fibbe et al., 2007; Gerdoni et al., 2007). In the ischemic brain, MSCs transplantation has been demonstrated to reduce the number of inflammatory cells (activated microglia and macrophages) (Kim et al., 2008). By reducing microglial expansion, MSC transplantation may reduce the inflammatory response, thus favoring the generation and integration of new neurons. MSC transplantation after acute traumatic brain injury in rats results in modulation of the inflammatory response by changing the expression of pro- and anti-inflammatory cytokines, along with modulation of serum levels of chemokines (Galindo et al., 2011). In a rat model of spinal cord injury, intravenously transplanted MSCs decrease the level of the pro-inflammatory cytokine IL-1 $\beta$, reduced the number of activated microglia, and increased the level of anti-inflammatory IL-10 (Seo and Cho, 2012). Additionally, a recent spinal cord injury study showed that, similar to the actions described for hAECs, MSCs induced a shift in macrophages from M1 pro-inflammatory phenotype, to a $\mathrm{M} 2$ anti-inflammatory state, thereby promoting a protective and regenerative response (Busch et al., 2011).

Finally, as was described for the actions of EPCs, a principal aspect of regeneration in the injured brain is angiogenesis and vascular remodeling. In a rat model of stroke, intravenously injected MSCs were shown to migrate selectively toward ischemic areas of damaged brain to increase angiogenesis and improve functional recovery (Chen and Keating, 2001; Li et al., 2002). Evidence shows that these cells not only produce the appropriate cytokine milieu necessary to promote an angiogenic response, but they secrete pro-angiogenic factors such as VEGF, and regulate other trophic support for angiogenesis such as basic fibroblast growth factor (bFGF), BMP-2, angiogenin and IL-6. Interestingly, MSCs may also have the capacity to differentiate into endothelial cells (Miranville et al., 2004; Rehman et al., 2004; Potapova et al., 2007).

\section{MSCs IN PREGNANCY AND THE FETUS}

MSCs can be detected in fetal blood from between 7 and 13 weeks gestation, with fetal MSCs being shown to have a characteristic morphology and immunophenotype (Campagnoli et al., 2001). Fetal MSCs are readily expandable in vitro and, as for adult bone marrow MSCs, they have the capacity to differentiate into a number of mesenchymal lineages (Pittenger et al., 1999; Reyes and Verfaillie, 2001; Devine, 2002). In the human fetus, circulating MSCs and EPCs appear at different gestational ages; at preterm 24-28 weeks gestational age, there is a significantly higher concentration of MSCs compared to EPCs within human UCB, which then switches in term gestation UCB. Accordingly, the concentration of MSCs decreases as human gestation proceeds to term, leading to a near absence of MSCs in 37-40 weeks UCB (Javed et al., 2008).

Despite the therapeutic potential that MSCs have demonstrated in adult brain injury, presently, there are only a handful of studies exploring the protective benefits of MSCs administered to the newborn. Studies arising from The Netherlands have guided the elucidation of the neuroprotective benefits of MSCs in the newborn brain; van Velthoven et al. (2011a) first demonstrated that bone-marrow derived MSCs administered in response to neonatal acute hypoxic ischemic brain damage improved functional outcome and reduced brain 
lesion volume. MSC-treated mice showed a decrease in the number of proliferating microglia in the lesioned hemisphere, decreased expression of proinflammatory cytokines in the ischemic hemisphere, and increased differentiation of neurons and oligodendrocytes (van Velthoven et al., 2011a,b). Most recently this group demonstrated that, in this acute newborn hypoxic-ischemic injury model, MSCs could be effectively administered intra-nasally and maintain their functional and structural neuroprotective benefits (Donega et al., 2013). Similarly, it has been reported that MSCs derived from human UCB and administered intra-cerebrally were able to ameliorate neonatal rat hypoxic-ischemic brain injury, with MSC-treated animals showing improved neurological score and differentiation of MSCs into astrocytes but not neurons (Xia et al., 2010). In a model of neonatal hyperoxic lung injury, intra-tracheal transplantation of human UCB-derived MSCs attenuated lung injury in neonatal rats, in a time-dependent manner, showing significant protection in the early inflammatory phase (Chang et al., 2013). To our knowledge, the only currently reported human study evaluating the therapeutic potential of MSCs on brain injury is a recent investigation in which umbilical cord MSCs were administered to a 5-years-old girl with established cerebral palsy. The patient was given 7 transplantations of MSCs over a 6-month period, and was followed for 28 months after the final transplantation. Specifically, the study reported a reduction of ambulation with tumble, with the patient being able to stand up by herself, as well as other improvements such as enhanced immunity, increased physical strength, and adjusted speech and comprehension (Wang et al., 2013a).

\section{CONCLUSIONS}

Without question, stem cells therapies hold promise for the treatment of a wide range of neurological disorders, including for

\section{REFERENCES}

Akiyama, K., Chen, C., Wang, D., $\mathrm{Xu}$, X., Qu, C., Yamaza, T., et al. (2012). Mesenchymal-stemcell-induced immunoregulation involves FAS-ligand-/FAS-mediated $\mathrm{T}$ cell apoptosis. Cell Stem Cell 10, 544-555. doi: 10.1016/j.stem.2012. 03.007

Akle, C. A., Adinolfi, M., Welsh, K. I., Leibowitz, S., and McColl, I. (1981). Immunogenicity of human amniotic epithelial cells after transplantation into volunteers. Lancet 2, 1003-1005. doi: 10.1016/S01406736(81)91212-5

Alexanian, A. R., Maiman, D. J., Kurpad, S. N., and Gennarelli, T. A. (2008). In vitro and in vivo characterization of neurally modified mesenchymal stem cells induced by epigenetic modifiers and neural stem cell environment. Stem Cells Dev. 17, 1123-1130. doi: 10.1089/scd.20 07.0212

Ali, H., and Bahbahani, H. (2010). Umbilical cord blood stem cells - potential therapeutic tool for neural injuries and disorders. Acta Neurobiol. Exp. (Wars) 70, 316-324.

Andressen, C. (2013). Neural stem cells: from neurobiology to clinical applications. Curr. Pharm. Biotechnol. 14, 20-28. doi: 10.2174/13892010 11314010005

Asahara, T., Murohara, T., Sullivan, A., Silver, M., van der Zee, R., Li, T., et al. (1997). Isolation of putative progenitor endothelial cells for angiogenesis. Science 275, 964-967. doi: 10.1126/science.275. 5302.964

Au, P., Daheron, L. M., Duda, D. G., Cohen, K. S., Tyrrell, J. A., Lanning, R. M., et al. (2008). Differential in vivo potential of endothelial progenitor cells from human umbilical cord blood and adult peripheral blood to form functional long-lasting vessels. Blood 111, 1302-1305. doi: 10.1182/blood2007-06-094318

Azzopardi, D., and Edwards, A. D. (2010). Magnetic resonance

the treatment of perinatal brain injuries. Indeed the potential and great hope placed in stem cells likely underlies the new trend of "stem cell tourism." But, as indicated in this review, there remains many and varied unresolved or not yet addressed important questions about the timing, appropriate cell types, treatment strategies, and appropriate outcomes that must still be addressed before such cells can be safely used in clinical translation studies. Have we yet adequately explored the long-term safety of cord blood or hAECs administered to babies or children? Over the past several years experimental animal studies have provided essential insight into the efficacy and potential mechanisms of stem cell therapies to protect and repair the adult brain, yet there is still a relative lack of translational research using experimental models of fetal and neonatal brain injury. Despite this, and as shown in Table $\mathbf{1}$, there are a number of clinical trials being conducted throughout the world investigating the effects of UCB on acquired brain injury in the newborn. An in depth examination of the safety and efficacy of stem cells in experimental models of fetal and neonatal brain injury is urgently needed in order to advance stem cell therapy from the laboratory to the clinic. More importantly, there is currently no consensus regarding the optimal dose, mode of delivery and the timing of stem cell treatment, which are likely to result in the greatest improvement of neurological outcome, thus highlighting the importance of future pre-clinical studies will well-defined outcomes.

\section{ACKNOWLEDGMENTS}

The authors wish to acknowledge funding support from Heart Foundation Australia, Inner Wheel Australia, Lynne Quayle Charitable Trust and Walter Cottman Endowment as administered by Equity Trustees, and the Victorian Government's Operational Infrastructure Support Program.

biomarkers of neuroprotective effects in infants with hypoxic ischemic encephalopathy. Semin. Fetal Neonatal Med. 15, 261-269. doi: 10.1016/j.siny.2010.03.001

Bailo, M., Soncini, M., Vertua, E., Signoroni, P. B., Sanzone, S. Lombardi, G., et al. (2004). Engraftment potential of human amnion and chorion cells derived from term placenta. Transplantation 78, 1439-1448. doi: 10.1097/01.TP. 0000144606.84234 .49

Baumhakel, M., Werner, N., Bohm, M., and Nickenig, G. (2006). Circulating endothelial progenitor cells correlate with erectile function in patients with coronary heart disease. Eur. Heart J. 27, 2184-2188. doi: 10.1093/eurheartj/ehl202

Bennet, L., Roelfsema, V., Dean, J. M., Wassink, G., Power, G. G., Jensen, E. C., et al. (2007). Regulation of cytochrome oxidase redox state during umbilical cord occlusion in preterm fetal sheep. Am. J. Physiol. Regul. Integr. Comp.
Physiol. 292, R1569-R1576. doi: 10.1152/ajpregu.00743.2006

Berger, R., and Garnier, Y. (2000). Perinatal brain injury. J. Perinat. Med. 28, 261-285. doi: 10.1515/JPM.2000.034

Berry, M. F., Engler, A. J., Woo, Y. J., Pirolli, T. J., Bish, L. T., Jayasankar, V., et al. (2006). Mesenchymal stem cell injection after myocardial infarction improves myocardial compliance. Am. J. Physiol. Heart Circ. Physiol. 290, H2196-H2203. doi: 10.1152/ajpheart.01017.2005

Borghesi, A., Massa, M., Campanelli, R., Bollani, L., Tzialla, C., Figar, T. A., et al. (2009). Circulating endothelial progenitor cells in preterm infants with bronchopulmonary dysplasia. Am. J. Respir. Crit. Care Med. 180, 540-546. doi: 10.1164/rccm.200812-19490C

Broughton, B. R., Lim, R., Arumugam, T. V., Drummond, G. R., Wallace, E. M., and Sobey, C. G. (2013). Post-stroke inflammation and the potential efficacy of novel stem 
cell therapies: focus on amnion epithelial cells. Front. Cell. Neurosci. 6:66. doi: 10.3389/fncel.2012. 00066

Broxmeyer, H. E., Douglas, G. W., Hangoc, G., Cooper, S., Bard, J., English, D., et al. (1989). Human umbilical cord blood as a potential source of transplantable hematopoietic stem/progenitor cells. Proc. Natl. Acad. Sci. U.S.A. 86, 3828-3832. doi: $10.1073 /$ pnas.86.10.3828

Busch, S. A., Hamilton, J. A., Horn, K. P., Cuascut, F. X., Cutrone, R., Lehman, N., et al. (2011). Multipotent adult progenitor cells prevent macrophage-mediated axonal dieback and promote regrowth after spinal cord injury. J. Neurosci. 31, 944-953. doi: 10. 1523/JNEUROSCI.3566-10.2011

Buzanska, L., Jurga, M., Stachowiak, E. K., Stachowiak, M. K., and Domanska-Janik, K. (2006). Neural stem-like cell line derived from a nonhematopoietic population of human umbilical cord blood. Stem Cells Dev. 15, 391-406. doi: 10.1089/scd.2006.15.391

Campagnoli, C., Roberts, I., Kumar, S., Bennett, P. R., and Fisk, N. M. (2001). Clonal culture of fetal cells from maternal blood. Lancet 357, 962. doi: 10.1016/S0140-6736 (05)71666-4

Caplan, A. I., and Dennis, J. E. (2006). Mesenchymal stem cells as trophic mediators. J. Cell. Biochem. 98, 1076-1084. doi: 10.1002/jcb. 20886

Chang, Y. S., Choi, S. J., Ahn, S. Y., Sung, D. K., Sung, S. I., Yoo, H. S., et al. (2013). Timing of umbilical cord blood derived mesenchymal stem cells transplantation determines therapeutic efficacy in the neonatal hyperoxic lung injury. PLOS ONE 8:e52419. doi: 10.1371/journal.pone.0052419

Chen, C. I., and Keating, A. (2001). Beyond bone marrow: a new source of stem cells. CMAJ 164, 683. doi: 10.1097/PRS.0b013e31818236b7

Daadi, M. M., Hu, S., Klausner, J., Li, Z., Sofilos, M., Sun, G., et al. (2013). Imaging neural stem cell graft-induced structural repair in stroke. Cell Transplant. 41, 516-526. doi: 10.3727/096368912X656144

De Coppi, P., Bartsch, G. Jr., Siddiqui, M. M., Xu, T., Santos, C. C., Perin, L., et al. (2007). Isolation of amniotic stem cell lines with potential for therapy. Nat. Biotechnol. 25, 100-106. doi: 10.1038/nbt1274

Deng, J., Petersen, B. E., Steindler, D. A., Jorgensen, M. L., and Laywell, E. D. (2006). Mesenchymal stem cells spontaneously express neural proteins in culture and are neurogenic after transplantation. Stem Cells 24, 1054-1064. doi: 10.1634/stemcells.2005-0370

de Paula, S., Greggio, S., Marinowic, D. R., Machado, D. C., and DaCosta, J. C. (2012). The dose-response effect of acute intravenous transplantation of human umbilical cord blood cells on brain damage and spatial memory deficits in neonatal hypoxia-ischemia. Neuroscience 210, 431-441. doi: 10.1016/j.neuro science.2012.03.009

Devine, S. M. (2002). Mesenchymal stem cells: will they have a role in the clinic. J. Cell. Biochem. Suppl. 38, 73-79. doi: 10.1002/jcb. 10046

Donega, V., van Velthoven, C. T., Nijboer, C. H., van Bel, F., Kas, M. J., Kavelaars, A., et al. (2013). Intranasal mesenchymal stem cell treatment for neonatal brain damage: long-term cognitive and sensorimotor improvement. PLoS ONE 8:e51253. doi: 10.1371/ journal.pone.0051253

Edwards, A. D., Brocklehurst, P., Gunn, A. J., Halliday, H., Juszczak, E., Levene, M., et al. (2010). Neurological outcomes at 18 months of age after moderate hypothermia for perinatal hypoxic ischaemic encephalopathy: synthesis and meta-analysis of trial data. BMJ 340, c363. doi: 10.1136/ bmj.c363

Elwan, M. A., Thangavel, R., Ono, F., and Sakuragawa, N. (1998). Synthesis and release of catecholamines by cultured monkey amniotic epithelial cells. J. Neurosci. Res. 53, 107-113. doi: 10.1002/ (SICI)1097-4547(19980701)53:1< 107::AID-JNR11>3.0.CO;2-6

Fan, Y., Shen, F., Frenzel, T., Zhu, W., Ye, J., Liu, J., et al. (2010). Endothelial progenitor cell transplantation improves longterm stroke outcome in mice. Ann. Neurol. 67, 488-497. doi: 10.1002/ana.21919

Felling, R. J., Snyder, M. J., Romanko, M. J., Rothstein, R. P., Ziegler, A. N., Yang, Z., et al. (2006). Neural stem/progenitor cells participate in the regenerative response to perinatal hypoxia/ischemia. J. Neurosci. 26, 4359-4369. doi: 10.1523/JNEUROSCI.1898-05.2006

Ferriero, D. M. (2004). Neonatal brain injury. N. Engl. J. Med. 351, 1985-1995. doi: 10.1056/NEJMra 041996

Fibbe, W. E., Nauta, A. J., and Roelofs, H. (2007). Modulation of immune responses by mesenchymal stem cells. Ann. N.Y. Acad. Sci. 1106, 272-278. doi: 10.1196/annals.13 92.025

Galindo, L. T., Filippo, T. R., Semedo, P., Ariza, C. B., Moreira, C. M. Camara, N. O., and Porcionatto, M. A. (2011). Mesenchymal stem cell therapy modulates the inflammatory response in experimental traumatic brain injury. Neurol. Res. Int. 2011, 564089. doi: 10.1155/2011/564089

Geissler, M., Dinse, H. R., Neuhoff, S., Kreikemeier, K., and Meier, C. (2011). Human umbilical cord blood cells restore brain damage induced changes in rat somatosensory cortex. PLOS ONE 6:e20194. doi: 10.1371/journal.pone.0020194

Gerdoni, E., Gallo, B., Casazza, S. Musio, S., Bonanni, I., Pedemonte, E., et al. (2007). Mesenchymal stem cells effectively modulate pathogenic immune response in experimental autoimmune encephalomyelitis. Ann. Neurol. 61, 219-227. doi: 10.1002/ana.21076

Gluckman, E., Broxmeyer, H. A., Auerbach, A. D., Friedman, H. S., Douglas, G. W., Devergie, A., et al. (1989). Hematopoietic reconstitution in a patient with Fanconi's anemia by means of umbilical-cord blood from an HLA-identical sibling. N. Engl. J. Med. 321, 1174-1178. doi: 10.1056/NEJM198910263211707

Gunn, A. J., Battin, M., Gluckman, P. D., Gunn, T. R., and Bennet, L. (2005). Therapeutic hypothermia: from lab to NICU. J. Perinat. Med. 33, 340-346. doi: 10.1515/JPM.2005.061

Gunn, A. J., and Bennet, L. (2009). Fetal hypoxia insults and patterns of brain injury: insights from animal models. Clin. Perinatol. 36, 579-593. doi: 10.1016/j.clp.2009. 06.007

Gunn, A. J., Gluckman, P. D., and Gunn, T. R. (1998). Selective head cooling in newborn infants after perinatal asphyxia: a safety study. Pediatrics 102, 885-892. doi: 10.1542/peds.102.4.885

Gunn, A. J., and Thoresen, M. (2006). Hypothermic neuroprotection. NeuroRx 3, 154-169. doi: 10.1016/j.nurx.2006.01.007

Gussin, H. A., Bischoff, F. Z., Hoffman, R., and Elias, S. (2002). Endothelial precursor cells in the peripheral blood of pregnant women. J. Soc. Gynecol. Investig. 9, 357-361. doi: 10.1016/S1071-5576(02)00188-0

Harris, D. T., and Rogers, I. (2007). Umbilical cord blood: a unique source of pluripotent stem cells for regenerative medicine. Curr. Stem
Cell Res. Ther. 2, 301-309. doi: 10.2174/157488807782793790

Harris, M. N., Carey, W. A., Ellsworth, M. A., Haas, L. R., Hartman, T. K., Lang, T. R., et al. (2013). Perceptions and practices of therapeutic hypothermia in American neonatal intensive care units. Am. J. Perinatol. doi: 10.1055/s-0033-133 4454. [Epub ahead of print].

Hebertson, R. M., Hammond, M. E., and Bryson, M. J. (1986). Amniotic epithelial ultrastructure in normal, polyhydramnic, and oligohydramnic pregnancies. Obstet. Gynecol. 68, 74-79.

Hermann, A., List, C., Habisch, H. J., Vukicevic, V., Ehrhart-Bornstein, M., Brenner, R., et al. (2010). Age-dependent neuroectodermal differentiation capacity of human mesenchymal stromal cells: limitations for autologous cell replacement strategies. Cytotherapy 12, 17-30. doi: 10.3109/1465324 0903313941

Herranz, A. S., Gonzalo-Gobernado, R., Reimers, D., Asensio, M. J., Rodriguez-Serrano, M., and Bazan, E. (2010). Applications of human umbilical cord blood cells in central nervous system regeneration. Curr. Stem Cell Res. Ther. 5, 17-22. doi: 10.2174/157488810790442822

Higgins, R. D., Raju, T., Edwards, A. D., Azzopardi, D. V., Bose, C. L., Clark, R. H., et al. (2011). Hypothermia and other treatment options for neonatal encephalopathy: an executive summary of the Eunice Kennedy Shriver NICHD workshop. J. Pediatr. 159, 851-858.e1. doi: 10.1016/j.jpeds.2011.08.004

Hipp, J., and Atala, A. (2006). "GeneChips in regenerative medicine," in Principles of Regenerative Medicine, eds A. Atala, R. Lanza, J. Thomson, and R. Nerem (Philadelphia, PA: Elsevier), 562-578.

Hodges, R. J., Jenkin, G., Hooper, S. B., Allison, B., Lim, R., Dickinson, H., et al. (2012). Human amnion epithelial cells reduce ventilationinduced preterm lung injury in fetal sheep. Am. J. Obstet. Gynecol. 206, 448.e8-448.e15. doi: 10.1016/j.ajog.2012.02.038

Horn, M., and Schlote, W. (1992). [Cerebral resuscitation]. Z. Gesamte Inn. Med. 47, 115-126.

Hristov, M., and Weber, C. (2004). Endothelial progenitor cells: characterization, pathophysiology, and possible clinical relevance. J. Cell. Mol. Med. 8, 498-508. doi: 10.1111/ j.1582-4934.2004.tb00474.x

Ilancheran, S., Michalska, A., Peh, G., Wallace, E. M., Pera, M., and 
Manuelpillai, U. (2007). Stem cells derived from human fetal membranes display multilineage differentiation potential. Biol. Reprod. 77, 577-588. doi: 10.1095/biolreprod. 106.055244

Ingram, D. A., Mead, L. E., Tanaka, H., Meade, V., Fenoglio, A., Mortell, K., et al. (2004). Identification of a novel hierarchy of endothelial progenitor cells using human peripheral and umbilical cord blood. Blood 104, 2752-2760. doi: 10.1182/blood-2004-04-1396

Itoo, B. A., Al-Hawsawi, Z. M., and Khan, A. H. (2003). Hypoxic ischemic encephalopathy. Incidence and risk factors in North Western Saudi Arabia. Saudi Med. J. 24, 147-153. doi: 10.1016/j.earlhum dev.2010.05.010

Iwasaki, R., Matsubara, S., Takizawa, T., Takayama, T., Yashiro, T., and Suzuki, M. (2003). Human amniotic epithelial cells are morphologically homogeneous: enzymehistochemical, tracer, and freeze-substitution fixation study. Eur. J. Histochem. 47, 223-232. doi: 10.4081/831

Javed, M. J., Mead, L. E., Prater, D., Bessler, W. K., Foster, D., Case, J., et al. (2008). Endothelial colony forming cells and mesenchymal stem cells are enriched at different gestational ages in human umbilical cord blood. Pediatr. Res. 64, 68-73. doi: 10.1203/PDR.0b013e31817445e9

Johnston, M. V., Fatemi, A., Wilson, M. A., and Northington, F. (2011). Treatment advances in neonatal neuroprotection and neurointensive care. Lancet Neurol. 10, 372-382. doi: 10.1016/S1474-4422 (11) $70016-3$

Kakishita, K., Elwan, M. A., Nakao, N., Itakura, T., and Sakuragawa, N. (2000). Human amniotic epithelial cells produce dopamine and survive after implantation into the striatum of a rat model of Parkinson's disease: a potential source of donor for transplantation therapy. Exp. Neurol. 165, 27-34. doi: 10.1006/exnr.2000.7449

Katz, L. M., Young, A. S., Frank, J. E., Wang, Y., and Park, K. (2004). Regulated hypothermia reduces brain oxidative stress after hypoxicischemia. Brain Res. 1017, 85-91. doi: 10.1016/j.brainres.2004.05.020

Kennea, N. L., Waddington, S. N., Chan, J., O'Donoghue, K., Yeung, D., Taylor, D. L., et al. (2013). Differentiation of human fetal mesenchymal stem cells into cells with an oligodendrocyte phenotype. Cell Cycle 8, 1069-1079. doi: 10.4161/cc.8.7.8121
Kim, D., Chun, B. G., Kim, Y. K., Lee, Y. H., Park, C. S., Jeon, I., et al. (2008). In vivo tracking of human mesenchymal stem cells in experimental stroke. Cell Transplant. 16, 1007-1012. doi: 10.3727/000000007783472381

Kim, H. J., Lee, J. H., and Kim, S. H. (2010). Therapeutic effects of human mesenchymal stem cells on traumatic brain injury in rats: secretion of neurotrophic factors and inhibition of apoptosis. J. Neurotrauma 27, 131-138. doi: 10.1089/neu.2008.0818

Kitada, M., and Dezawa, M. (2012). Parkinson's disease and mesenchymal stem cells: potential for cell-based therapy. Parkinsons Dis. 2012:873706. doi: 10.1155/2012/ 873706

Kurtzberg, J. (1996). Umbilical cord blood: a novel alternative source of hematopoietic stem cells for bone marrow transplantation. J. Hematother. 5, 95-96. doi: 10.1089/scd.1.1996.5.95

Le Blanc, K. (2003). Immunomodulatory effects of fetal and adult mesenchymal stem cells. Cytotherapy 5, 485-489. doi: 10. 1080/14653240310003611

Leviton, A., and Paneth, N. (1990). White matter damage in preterm newborns-an epidemiologic perspective. Early Hum. Dev. 24, 1-22. doi: 10.1016/0378-3782(90) 90002-Z

Li, H., Niederkorn, J. Y., Neelam, S., Mayhew, E., Word, R. A., McCulley, J. P., et al. (2005). Immunosuppressive factors secreted by human amniotic epithelial cells. Invest. Ophthalmol. Vis. Sci. 46, 900-907. doi: 10.1167/ iovs.04-0495

Li, J., Zhu, H., Liu, Y., Li, Q., Lu, S., Feng, M., et al. (2010). Human mesenchymal stem cell transplantation protects against cerebral ischemic injury and upregulates interleukin10 expression in Macacafascicularis. Brain Res. 1334, 65-72. doi: 10.1016/j.brainres.2010.03.080

Li, S. F., Lu, X. F., and Sun, M. H. (2002). [Biological characteristics of mesenchymal stem cells in vitro derived from bone marrow of banna minipig inbred line]. Zhongguo Xiu Fu Chong Jian Wai Ke Za Zhi 16, 354-358.

Liu, T., Wu, J., Huang, Q., Hou, Y., Jiang, Z., Zang, S., et al. (2008). Human amniotic epithelial cells ameliorate behavioral dysfunction and reduce infarct size in the rat middle cerebral artery occlusion model. Shock 29, 603-611. doi: 10.1097/SHK.0b013e318157e845
Locatelli, F., Rocha, V., Chastang, C., Arcese, W., Ortega, J., Pasquini, R., et al. (1998). Cord blood transplantation for children with acute leukemia. Eurocord transplant group. Bone Marrow Transplant. 21(Suppl. 3), S63-S65.

Mahmood, A., Lu, D., Qu, C., Goussev, A., and Chopp, M. (2005). Human marrow stromal cell treatment provides long-lasting benefit after traumatic brain injury in rats. Neurosurgery 57, 1026-1031. discussion: 1026-1031. doi: 10.1227/ 01.NEU.0000181369.76323.50

Mamede, A. C., Carvalho, M. J., Abrantes, A. M., Laranjo, M., Maia, C. J., and Botelho, M. F (2012). Amniotic membrane: from structure and functions to clinical applications. Cell Tissue Res. 349, 447-458. doi: 10.1007/s00441-0121424-6

Massaro, A. N., Bouyssi-Kobar, M., Chang, T., Vezina, L. G., du Plessis, A. J., and Limperopoulos, C. (2013). Brain perfusion in encephalopathic newborns after therapeutic hypothermia. Am. J. Neuroradiol. 34, 1649-1655. doi: 10.3174/ajnr.A3422

Miller, S. L., Yan, E. B., CastilloMelendez, M., Jenkin, G., and Walker, D. W. (2005). Melatonin provides neuroprotection in the late-gestation fetal sheep brain in response to umbilical cord occlusion. Dev. Neurosci. 27, 200-210. doi: $10.1159 / 000085993$

Miranville, A., Heeschen, C., Sengenes, C., Curat, C. A., Busse, R., and Bouloumie, A. (2004) Improvement of postnatal neovascularization by human adipose tissue-derived stem cells. Circulation 110, 349-355. doi: 10.1161/01.CIR. 0000135466.16823.D0

Munoz, J. L., Greco, S. J., Patel, S. A., Sherman, L. S., Bhatt, S. Bhatt, R. S., et al. (2012). Feline bone marrow-derived mesenchymal stromal cells (MSCs) show similar phenotype and functions with regards to neuronal differentiation as human MSCs. Differentiation 84, 214-222. doi: 10.1016/j.diff.2012.07.002

Munoz, J. R., Stoutenger, B. R., Robinson, A. P., Spees, J. L., and Prockop, D. J. (2005). Human stem/progenitor cells from bone marrow promote neurogenesis of endogenous neural stem cells in the hippocampus of mice. Proc. Natl. Acad. Sci. U.S.A. 102, 18171-18176. doi: 10.1073/pnas.0508945102

Murphy, S., Rosli, S., Acharya, R., Mathias, L., Lim, R., Wallace, E., et al. (2010). Amnion epithelial cell isolation and characterization for clinical use. Curr. Protoc. Stem Cell Biol. Chapter 1, Unit 1E 6. doi: 10.1002/9780470151808.sc01e06s13

Ohta, T., Kikuta, K., Imamura, H., Takagi, Y., Nishimura, M., Arakawa, Y., et al. (2006). Administration of ex vivo-expanded bone marrowderived endothelial progenitor cells attenuates focal cerebral ischemia-reperfusion injury in rats. Neurosurgery 59, 679-686. doi: 10. 1227/01.NEU.0000229058.08706.88

Paolo, T. (2012). The high-risk newborns. J. Matern. Fetal. Neonatal. Med. 25(Suppl. 1), 6-7. doi 10.3109/14767058.2012.664893

Parolini, O., Alviano, F., Bagnara, G. P., Bilic, G., Buhring, H. J., Evangelista, M., et al. (2008). Concise review: isolation and characterization of cells from human term placenta: outcome of the first international workshop on placenta derived stem cells. Stem Cells 26, 300-311. doi: 10.1634/stemcells.2007-0594

Parr, A. M., Tator, C. H., and Keating, A. (2007). Bone marrow-derived mesenchymal stromal cells for the repair of central nervous system injury. Bone Marrow Transplant. 40, 609-619. doi: 10.1038/sj.bmt. 1705757

Peichev, M., Naiyer, A. J., Pereira, D., Zhu, Z., Lane, W. J., Williams, M. et al. (2000). Expression of VEGFR2 and AC133 by circulating human CD34(+) cells identifies a population of functional endothelial precursors. Blood 95, 952-958. doi: 10.1016/S0008-6363(03)00252-9

Penrice, J., and Nussey, S. S. (1992). Recovery of adrenocortical function following treatment of tuberculous Addison's disease. Postgrad. Med. J. 68, 204-205. doi: 10.1136/pgmj.68. 797.204

Perlman, J. M. (2004). Brain injury in the term infant. Semin. Perinatol. 28, 415-424. doi: 10.1053/j.semperi. 2004.10.003

Pimentel-Coelho, P. M., Rosado-deCastro, P. H., da Fonseca, L. M., and Mendez-Otero, R. (2012). Umbilical cord blood mononuclear cell transplantation for neonatal hypoxicischemic encephalopathy. Pediatr Res. 71, 464-473. doi: 10.1038/pr. 2011.59

Pipes, B. L., and Ablin, R. J. (2006). Embryonic stem cell cotransplantation revisited: utility of umbilical cord blood "embryoniclike" stem cells. Ann. Clin. Lab. Sci. 36, 105-106. doi: 10.2217/1746 0751.1.6.777

Pittenger, M. F., Mackay, A. M., Beck, S. C., Jaiswal, R. K., Douglas, 
R., Mosca, J. D., et al. (1999). Multilineage potential of adult human mesenchymal stem cells. Science 284, 143-147. doi: 10.1126/science.284.5411.143

Potapova, I. A., Gaudette, G. R., Brink, P. R., Robinson, R. B., Rosen, M. R., Cohen, I. S., et al. (2007). Mesenchymal stem cells support migration, extracellular matrix invasion, proliferation, and survival of endothelial cells in vitro. Stem Cells 25, 1761-1768. doi: 10.1634/ stemcells.2007-0022

Red-Horse, K., Crawford, Y., Shojaei, F., and Ferrara, N. (2007). Endothelium-microenvironment interactions in the developing embryo and in the adult. Dev. Cell 12, 181-194. doi: 10.1016/j.devcel. 2007.01.013

Red-Horse, K., and Ferrara, N. (2006). Imaging tumor angiogenesis. J. Clin. Invest. 116, 2585-2587. doi: 10. 1172/JCI30058

Rehman, J., Traktuev, D., Li, J., Merfeld-Clauss, S., Temm-Grove, C. J., Bovenkerk, J. E., et al. (2004). Secretion of angiogenic and antiapoptotic factors by human adipose stromal cells. Circulation 109, 1292-1298. doi: 10.1161/01.CIR. 0000121425.42966.F1

Reyes, M., and Verfaillie, C. M. (2001). Characterization of multipotent adult progenitor cells, a subpopulation of mesenchymal stem cells. Ann. N.Y. Acad. Sci. 938, 231-233. discussion: 233-235. doi: 10.1111/j. 1749-6632.2001.tb03593.x

Reynolds, B. A., Tetzlaff, W., and Weiss, S. (1992). A multipotent EGF-responsive striatal embryonic progenitor cell produces neurons and astrocytes. J. Neurosci. 12, 4565-4574.

Rice, J. E. 3rd., Vannucci, R. C., and Brierley, J. B. (1981). The influence of immaturity on hypoxicischemic brain damage in the rat. Ann. Neurol. 9, 131-141. doi: 10. 1002/ana.410090206

Roth, S. C., Edwards, A. D., Cady, E. B., Delpy, D. T., Wyatt, J. S., Azzopardi, D., et al. (1992). Relation between cerebral oxidative metabolism following birth asphyxia, and neurodevelopmental outcome and brain growth at one year. Dev. Med. Child Neurol. 34, 285-295. doi: 10.1111/j.14698749.1992.tb11432.x

Sakuragawa, N., Misawa, H., Ohsugi, K., Kakishita, K., Ishii, T., Thangavel, R., et al. (1997). Evidence for active acetylcholine metabolism in human amniotic epithelial cells: applicable to intracerebral allografting for neurologic disease. Neurosci. Lett. 232, 53-56. doi: $\quad 10.1016 / S 0304-3940(97) 00$ 570-3

Sakuragawa, N., Thangavel, R. Mizuguchi, M., Hirasawa, M., and Kamo, I. (1996). Expression of markers for both neuronal and glial cells in human amniotic epithelial cells. Neurosci. Lett. 209, 9-12. doi: 10.1016/0304-3940(96)12599-4

Seo, J. H., and Cho, S. R. (2012). Neurorestoration induced by mesenchymal stem cells: potential therapeutic mechanisms for clinical trials. Yonsei Med. J. 53, 1059-1067. doi: 10.3349/ymj.2012.53.6.1059

Shankaran, S., Laptook, A. R., Ehrenkranz, R. A., Tyson, J. E., McDonald, S. A., Donovan, E. F., et al. (2005). Whole-body hypothermia for neonates with hypoxic-ischemic encephalopathy. N. Engl. J. Med. 353, 1574-1584. doi: 10.1056/NEJMcps050929

Simbruner, G., Mittal, R. A., Rohlmann, F., and Muche, R. (2010). Systemic hypothermia after neonatal encephalopathy: outcomes of neo.nEURO.network RCT. Pediatrics 126, e771-e778. doi: 10.1542/peds.2009-2441

Slatter, M. A., Bhattacharya, A., Flood, T. J., Abinun, M., Cant, A. J. and Gennery, A. R. (2006). Use of two unrelated umbilical cord stem cell units in stem cell transplantation for Wiskott-Aldrich syndrome. Pediatr. Blood Cancer 47, 332-334. doi: $10.1002 / p b c .20450$

Solomon, A., Rosenblatt, M., Monroy, D., Ji, Z., Pflugfelder, S. C., and Tseng, S. C. (2001). Suppression of interleukin lalpha and interleukin lbeta in human limbal epithelial cells cultured on the amniotic membrane stromal matrix. $\mathrm{Br}$. J. Ophthalmol. 85, 444-449. doi: 10.1136/bjo.85.4.444

Sommer, L., and Rao, M. (2002). Neural stem cells and regulation of cell number. Prog. Neurobiol. 66 1-18. doi: 10.1016/S0301-0082(01) 00022-3

Sugawara, J., Mitsui-Saito, M., Hoshiai, T., Hayashi, C., Kimura, Y., and Okamura, K. (2005). Circulating endothelial progenitor cells during human pregnancy. J. Clin. Endocrinol. Metab. 90, 1845-1848. doi: 10.1210/jc.2004-0541

Swijnenburg, R. J., Tanaka, M., Vogel, H., Baker, J., Kofidis, T., Gunawan, F., et al. (2005). Embryonic stem cell immunogenicity increases upon differentiation after transplantation into ischemic myocardium. Circulation 112(9 Suppl.), I166I172. doi: 10.1161/CIRCULATION AHA.104.525824
Tajiri, N., Acosta, S., Glover, L. E. Bickford, P. C., Jacotte Simancas, A., Yasuhara, T., et al. (2012) Intravenous grafts of amniotic fluid-derived stem cells induce endogenous cell proliferation and attenuate behavioral deficits in ischemic stroke rats. PLoS ONE 7:e43779. doi: 10.1371/journal. pone. 0043779

Tan, J. L., Chan, S. T., Wallace, E. M., and Lim, R. (2013). Human amnion epithelial cells mediate lung repair by directly modulating macrophage recruitment and polarization. Cell Transplant. doi: 10.3727/096368912 X661409. [Epub ahead of print].

Tepper, O. M., Galiano, R. D., Capla, J. M., Kalka, C., Gagne, P. J. Jacobowitz, G. R., et al. (2002). Human endothelial progenitor cells from type II diabetics exhibit impaired proliferation, adhesion, and incorporation into vascular structures. Circulation 106, 2781-2786. doi: 10.1161/01.CIR 0000039526.42991 .93

Titomanlio, L., Kavelaars, A., Dalous, J., Mani, S., El Ghouzzi, V., Heijnen, C., et al. (2011). Stem cell therapy for neonatal brain injury: perspectives and challenges. Ann. Neurol. 70, 698-712. doi: 10.1002/ana.22518

Tiwari, A., Tursky, M. L., Mushahary, D., Wasnik, S., Collier, F. M., Suma, K., et al. (2012). Ex vivo expansion of haematopoietic stem/progenitor cells from human umbilical cord blood on acellular scaffolds prepared from MS-5 stromal cell line. J. Tissue Eng. Regen. Med. doi: 10.1002/term.1479. [Epub ahead of print].

Toda, A., Okabe, M., Yoshida, T., and Nikaido, T. (2007). The potential of amniotic membrane/amnion-derived cells for regeneration of various tissues. J. Pharmacol. Sci. 105, 215-228. doi 10.1254/jphs.CR0070034

Tursky, M. L., Collier, F. M., Ward, A. C., and Kirkland, M. A. (2012). Systematic investigation of oxygen and growth factors in clinically valid ex vivo expansion of cord blood CD34(+) hematopoietic progenitor cells. Cytotherapy 14, 679-685. doi: 10.3109/14653249.2012.666851

Vannucci, R. C., and Perlman, J. M. (1997). Interventions for perinatal hypoxic-ischemic encephalopathy. Pediatrics 100, 1004-1014. doi 10.1542/peds.100.6.1004

van Velthoven, C. T., Kavelaars, A., van Bel, F., and Heijnen, C. J. (2011a). Mesenchymal stem cell treatment after neonatal hypoxic-ischemic brain injury improves behavioral outcome and induces neuronal and oligodendrocyte regeneration. Brain Behav. Immun. 24, 387-393. doi: 10.1016/j.bbi.2009. 10.017

van Velthoven, C. T., Kavelaars, A., van Bel, F., and Heijnen, C. J. (2011b). Mesenchymal stem cell transplantation changes the gene expression profile of the neonatal ischemic brain. Brain Behav. Immun. 25, 1342-1348. doi: 10.1016/j.bbi.2011 03.021

Vasa, M., Fichtlscherer, S., Aicher, A., Adler, K., Urbich, C., Martin, H., et al. (2001). Number and migratory activity of circulating endothelial progenitor cells inversely correlate with risk factors for coronary artery disease. Circ. Res. 89, E1-E7. doi: 10.1161/hc2401.092816

Volpe, J. J. (2001a). Perinatal brain injury: from pathogenesis to neuroprotection. Ment. Retard. Dev. Disabil. Res. Rev. 7, 56-64. doi: 10.1002/1098-2779(200102)7:1<56 ::AID-MRDD1008>3.0.CO;2-A

Volpe, J. J. (2001b). Neurobiology of periventricular leukomalacia in the premature infant. Pediatr. Res. 50, 553-562. doi: 10.1203/00006450200111000-00003

Volpe, J. J. (2012). Neonatal encephalopathy: an inadequate term for hypoxic-ischemic encephalopathy. Ann. Neurol. 72, 156-166. doi: 10.1002/ana.23647

Vosdoganes, P., Hodges, R. J., Lim, R., Westover, A. J., Acharya, R. Y., Wallace, E. M., et al. (2011). Human amnion epithelial cells as a treatment for inflammation-induced fetal lung injury in sheep. Am. J. Obstet. Gynecol. 205, 156.e26156.e33. doi: 10.1016/j.ajog.2011. 03.054

Vosdoganes, P., Wallace, E. M., Chan, S. T., Acharya, R., Moss, T. J., and Lim, R. (2012). Human amnion epithelial cells repair established lung injury. Cell Transplant. 22, 1337-1349. doi: 10.3727/096368912X657657

Wang, F., Maeda, N., Yasuhara, T., Kameda, M., Tsuru, E., Yamashita T., et al. (2012). The therapeutic potential of human umbilical cord blood transplantation for neonatal hypoxic-ischemic brain injury and ischemic stroke. Acta Med. Okayama 66, 429-434. doi: 10.1111/ j.1582-4934.2008.00671.x

Wang, L., Ji, H., Zhou, J., Xie, J. Zhong, Z., Li, M., et al. (2013a) Therapeutic potential of umbilical cord mesenchymal stromal cells transplantation for cerebral palsy: a case report. Case Rep. Transplant. 2013, 146347. doi: $10.1155 / 2013 / 146347$ 
Wang, X. L., Zhao, Y. S., Hu, M. Y., Sun, Y. Q., Chen, Y. X., and Bi, X. H. (2013b). Umbilical cord blood cells regulate endogenous neural stem cell proliferation via Hedgehog signaling in hypoxic-ischemic neonatal rats. Brain Res. 1518, 26-35. doi: 10.1016/j.brainres.2013.04.038

Wasielewski, B., Jensen, A., RothHarer, A., Dermietzel, R., and Meier, C. (2012). Neuroglial activation and $\mathrm{Cx} 43$ expression are reduced upon transplantation of human umbilical cord blood cells after perinatal hypoxic-ischemic injury. Brain Res. 1487, 39-53. doi: $\quad$ 10.1016/j.brainres.2012. 05.066

Werner, N., and Nickenig, G. (2006a). Influence of cardiovascular risk factors on endothelial progenitor cells: limitations for therapy. Arterioscler. Thromb. Vasc. Biol. 26, 257-266. doi: 10.1161/01.ATV.0000198239. $41189.5 \mathrm{~d}$

Werner, N., and Nickenig, G. (2006b). Clinical and therapeutical implications of EPC biology in atherosclerosis. J. Cell. Mol. Med. 10, 318-332. doi: 10.1111/j.15824934.2006.tb00402.x

Woodbury, D., Schwarz, E. J., Prockop, D. J., and Black, I. B. (2000). Adult rat and human bone marrow stromal cells differentiate into neurons. J. Neurosci. Res. 61, 364-370. doi: 10.1002/1097-4547(20000815) 61:4<364::AID-JNR2>3.0.CO;2-C

Xia, G., Hong, X., Chen, X., Lan, F., Zhang, G., and Liao, L. (2010).
Intracerebral transplantation of mesenchymal stem cells derived from human umbilical cord blood alleviates hypoxic ischemic brain injury in rat neonates. J. Perinat. Med. 38, 215-221. doi: 10.1515/jpm. 2010.021

Xin, H., Li, Y., Shen, L. H., Liu, X., Wang, X., Zhang, J., et al. (2010). Increasing tPA activity in astrocytes induced by multipotent mesenchymal stromal cells facilitate neurite outgrowth after stroke in the mouse. PLoS ONE 5:e9027. doi: 10.1371/journal.pone.0009027

Yang, X., Song, L., Wu, N., Liu, Z., Xue, S., and Hui, G. (2010) An experimental study on intracerebroventricular transplantation of human amniotic epithelial cells in a rat model of Parkinson's disease. Neurol. Res. 32, 1054-1059. doi: 10. 1179/016164110X12681290831207

Yawno, T., Schuilwerve, J., Moss, T. J. M., Vosdoganes, P., Westover, A. J., Afandi, E., et al. (2013). Human amnion epithelial cells reduce fetal brain injury in response to intrauterine inflammation. Dev. Neurosci. 35, 272-282. doi: 10.1159/ 000346683

Yi, E. S., Lee, S. H., Son, M. H., Kim, J. Y., Cho, E. J., Lim, S. J., et al. (2012). Hematopoietic stem cell transplantation in children with acute leukemia: similar outcomes in recipients of umbilical cord blood versus marrow or peripheral blood stem cells from related or unrelated donors. Korean J. Pediatr. 55,
93-99. doi: 10.3345/kjp.2012.55 3.93

Yoder, M. C., Mead, L. E., Prater D., Krier, T. R., Mroueh, K. N., Li, F., et al. (2007). Redefining endothelial progenitor cells via clonal analysis and hematopoietic stem/progenitor cell principals. Blood 109, 1801-1809. doi: 10.1182/blood-2006-08-043471

Yoon, B. H., Park, C. W., and Chaiworapongsa, T. (2003). Intrauterine infection and the development of cerebral palsy. BJOG 110(Suppl. 20), 124-127. doi: 10.1046/j.1471-0528.2003.00063.X

Yu, S. J., Soncini, M., Kaneko, Y., Hess, D. C., Parolini, O., and Borlongan, C. V. (2009). Amnion: a potent graft source for cell therapy in stroke. Cell Transplant. 18, 111-118. doi: 10.3727/096368909 788341243

Zampetaki, A., Kirton, J. P., and $\mathrm{Xu}$, Q. (2008). Vascular repair by endothelial progenitor cells. Cardiovasc. Res. 78, 413-421. doi: 10.1093/cvr/cvn081

Zhang, Z. G., Zhang, L., Jiang, Q. and Chopp, M. (2002). Bone marrow-derived endothelial progenitor cells participate in cerebral neovascularization after focal cerebral ischemia in the adult mouse. Circ. Res. 90, 284-288. doi: 10.1161/hh0302.104460

Zilka, N., Zilkova, M., Kazmerova, Z., Sarissky, M., Cigankova, V., and Novak, M. (2011). Mesenchymal stem cells rescue the Alzheimer's disease cell model from cell death induced by misfolded truncated tau. Neuroscience 193 330-337. doi: 10.1016/j.neuro science.2011.06.088

Conflict of Interest Statement: The authors declare that the research was conducted in the absence of any commercial or financial relationships that could be construed as a potential conflict of interest.

Received: 09 May 2013; accepted: 07 October 2013; published online: 24 October 2013.

Citation: Castillo-Melendez M, Yawno T, Jenkin G and Miller SL (2013) Stem cell therapy to protect and repair the developing brain: a review of mechanisms of action of cord blood and amnion epithelial derived cells. Front. Neurosci. 7:194 doi: 10.3389/fnins.2013.00194

This article was submitted to Neuroendocrine Science, a section of the journal Frontiers in Neuroscience. Copyright (C) 2013 Castillo-Melendez, Yawno, Jenkin and Miller. This is an open-access article distributed under the terms of the Creative Commons Attribution License (CC BY). The use, distribution or reproduction in other forums is permitted, provided the original author(s) or licensor are credited and that the original publication in this journal is cited, in accordance with accepted academic practice. No use, distribution or reproduction is permitted which does not comply with these terms. 